\title{
SPIROMETRIC EVALUATION OF ANTENATAL WOMEN AND THEIR OUTCOME AT A TERTIARY CARE CENTRE
}

\author{
Amar Karia1, Kshama Kedar², Radha Munje3, Nivedita Goverdhan ${ }^{4}$ \\ 1 Junior Resident, Department of Obstetrics and Gynaecology, Indira Gandhi Government Medical College, Nagpur. \\ ${ }^{2}$ Associate Professor, Department of Obstetrics and Gynaecology, Indira Gandhi Government Medical College, Nagpur. \\ ${ }_{3}^{3}$ Professor, Department of Respiratory Medicine, Indira Gandhi Government Medical College, Nagpur. \\ ${ }^{4}$ Senior Resident, Department of Obstetrics and Gynaecology, Indira Gandhi Government Medical College, Nagpur.
}

\begin{abstract}
BACKGROUND

Pregnancy represents one of the best examples of selective adaptation in terms of respiratory physiology. Understanding of the maternal pulmonary function and their precise knowledge allows the clinician to verify the extent of the adaptation in pregnant women and helps to avoid unnecessary treatment of physiological changes misinterpreted as pathological changes in reference to pre-pregnancy standards.

Objectives- This study was undertaken to identify physiological changes in respiratory system in normal and high-risk pregnancy, which may help in modifying mode of delivery and foetal outcome.
\end{abstract}

\section{MATERIALS AND METHODS}

This was a prospective longitudinal study, undertaken in the Department of Obstetrics and Gynaecology at Indira Gandhi Government Medical College, which is a tertiary care centre for over a period of 2 years, which included 100 antenatal patients between 19 to 35 years age and without any obstetric complications or pre-existing respiratory and cardiovascular disorders.

\section{RESULTS}

In this study the mean values of FVC, PEFR and MVV showed a significant decrease from first to third trimester; whereas there was a significant increase in the mean value of FEV1/FVC from first-to-third trimester. There was no significant difference in FEV1 in between the three trimesters of pregnancy.

\section{CONCLUSION}

The results obtained in our study suggest that in pregnant women at term respiratory distress is rarely sufficient to interfe re with ordinary physical activity. However, impaired pulmonary function in pregnant women may pose additional risk during parturition as well as during operative procedures like caesarean section, which require anaesthesia.

\section{KEYWORDS}

Spirometry, Pulmonary Function Tests, Antenatal Women, Respiratory Disorders.

HOW TO CITE THIS ARTICLE: Karia A, Kedar K, Munje R, et al. Spirometric evaluation of antenatal women and their outcome at a tertiary care centre. J. Evolution Med. Dent. Sci. 2017;6(42):3274-3277, DOI: 10.14260/Jemds/2017/709

\section{BACKGROUND \\ Pregnancy represents one of the best examples of selective adaptation in terms of respiratory physiology. ${ }^{1}$ The increasing size of the foetus with advancing gestation constitutes a mechanical impediment to normal process of maternal ventilation. ${ }^{2}$ Understanding of the maternal pulmonary function and their precise knowledge allows the clinician to verify the extent of the adaptation in pregnant women and helps to avoid unnecessary treatment of physiological changes misinterpreted as pathological changes in reference to pre-pregnancy standards. It also forms the essentials for administration of anaesthesia in complicated third trimester pregnancy management and caesarean sections.3,4,5 Disorders of respiratory system reduce}

Financial or Other, Competing Interest: None.

Submission 20-04-2017, Peer Review 14-05-2017,

Acceptance 20-05-2017, Published 25-05-2017.

Corresponding Author:

Dr. Amar Karia

Department of Obstetrics and Gynaecology,

Indira Gandhi Government Medical College,

Nagpur.

E-mail: amarkaria98@gmail.com

DOI: $10.14260 /$ jemds $/ 2017 / 709$

\section{(c) (i) $\ominus$}

pulmonary reserve and instrumental delivery may be required. Any deviation from these normal changes affects foetal outcome. Thus, an early identification of these deviations can modify foetal outcome and prevent neonatal morbidities.

To study these physiological changes and deviations from normal, a comparative study was undertaken to identify physiological changes in respiratory system in normal and high-risk pregnancy, which may help in modifying mode of delivery and foetal outcome.

\section{MATERIALS AND METHODS}

This was a prospective longitudinal study, undertaken in the Department of Obstetrics and Gynaecology at Indira Gandhi Government Medical College, which is a tertiary care centre for over a period of 2 years, which included 100 antenatal women between 19 to 35 years age and without any obstetric complications or pre-existing respiratory and cardio-vascular disorders. While women less than 19 and more than 35 and those having pre-existing respiratory and cardiovascular disorders were excluded.

After taking informed and written consent from each subject, and approval of Institutional Ethical Committee, detailed history was recorded and complete clinical 
examination was done at the beginning of study. Patients were called on specific dates between 8 - 12 weeks, $24-28$ weeks and then between $34-36$ weeks for doing the test. The equipment used for recording of Pulmonary Function Tests (PFT) was Computerised Medspiror. The parameters were recorded: Forced Vital Capacity (FVC), Forced Expiratory Volume in 1st second (FEV1), FEV1/FVC ratio, Peak Expiratory Flow Rate (PEFR), Maximum Voluntary Ventilation (MVV). Data was analysed using paired ' $\mathrm{t}$ ' test and ANOVA, P-value of less than 0.05 was taken as significant.

\section{RESULTS}

\begin{tabular}{|c|c|c|c|}
\hline \multicolumn{2}{|c|}{$\begin{array}{c}\text { Socio-Demographic } \\
\text { Parameters }\end{array}$} & $\begin{array}{c}\text { No. of } \\
\text { Patients }\end{array}$ & Mean \\
\hline \multirow{3}{*}{ Age (Years) } & $18-24$ & 51 & \multirow{3}{*}{$\begin{array}{l}24.88 \\
\text { Years }\end{array}$} \\
\hline & $24-30$ & 43 & \\
\hline & $>30$ & 6 & \\
\hline \multirow{3}{*}{ Gravidity } & Primi & 70 & \multirow{3}{*}{--} \\
\hline & Second & 24 & \\
\hline & Third & 6 & \\
\hline \multirow{4}{*}{ BMI $\left(\mathrm{kg} / \mathrm{m}^{2}\right)$} & $<20$ & 3 & \multirow{4}{*}{25.99} \\
\hline & $20.1-24.99$ & 30 & \\
\hline & $25.1-29.9$ & 59 & \\
\hline & $>30$ & 8 & \\
\hline Table 1. D & $\begin{array}{l}\text { ribution of Pc } \\
\text { Demographi }\end{array}$ & $\begin{array}{l}\text { its accord } \\
\text { rameters }\end{array}$ & ocio- \\
\hline
\end{tabular}

The age of pregnant women varied between 19 - 36 years. The mean age was 24.88 yrs. Majority of the women in the study, i.e. $70 \%$ were Primigravida. Majority of pregnant women, i.e. 59\% were overweight, (BMI- 25.1 - 29.9).

\begin{tabular}{|c|c|c|}
\hline \multicolumn{2}{|c|}{ Labour Parameters } & No. of Patients \\
\hline \multirow{3}{*}{ Mode of Delivery } & Instrumental & 9 \\
\cline { 2 - 3 } & LSCS & 28 \\
\cline { 2 - 3 } & Vaginal & 63 \\
\hline \multirow{2}{*}{ Foetal Outcome } & Live Birth & 98 \\
\cline { 2 - 3 } & Still Birth & 2 \\
\hline
\end{tabular}

Table 2. Distribution of Patients according to Labour Parameters

Most of the women in this study had uneventful vaginal delivery $(70 \%)$. There were 9 women who underwent instrumental delivery with the predominant indication being maternal exhaustion. Only 2\% women had Stillbirth. Rest 98\% women gave birth to live babies with good Apgar score.

\begin{tabular}{|c|c|c|c|c|}
\hline Parameter & $\begin{array}{c}\text { 1st } \\
\text { Trimester }\end{array}$ & $\begin{array}{c}\text { 2nd } \\
\text { Trimester }\end{array}$ & $\begin{array}{c}\text { 3rd } \\
\text { Trimester }\end{array}$ & P-value \\
\hline $\begin{array}{c}\text { FVC } \\
\text { (Lit/min) }\end{array}$ & $2.35 \pm 0.10$ & $2.21 \pm 012$ & $2.15 \pm 0.13$ & $<0.05, \mathrm{HS}$ \\
\hline $\begin{array}{c}\text { FEV1 } \\
\text { (Lit/min) }\end{array}$ & $2.256 \pm 0.07$ & $2.250 \pm 0.07$ & $2.256 \pm 0.08$ & $0.14, \mathrm{NS}$ \\
\hline $\begin{array}{c}\text { FEV1/ } \\
\text { FVC } \%\end{array}$ & $96.16 \pm 5.75$ & $101.99 \pm 6.23$ & $105.25 \pm 7.02$ & $<0.05, \mathrm{HS}$ \\
\hline $\begin{array}{c}\text { PEFR } \\
\text { (Lit/sec) }\end{array}$ & $5.31 \pm 0.23$ & $4.67 \pm 0.24$ & $4.24 \pm 0.27$ & $<0.05, \mathrm{HS}$ \\
\hline $\begin{array}{c}\text { MVV } \\
(\mathrm{Lit} / \mathrm{min})\end{array}$ & $73.24 \pm 4.88$ & $65.63 \pm 4.75$ & $61.05 \pm 5.59$ & $<0.05, \mathrm{HS}$ \\
\hline Table 3. Comparison of all Pulmonary Function Tests \\
with Trimesters of Pregnancy \\
\hline \multicolumn{5}{|c|}{} \\
\hline
\end{tabular}

Table No. 3 compares all the parameters of pulmonary function with trimesters of pregnancy with FVC, FEV1/FVC, PEFR and MVV showing a statistically significant difference in between the trimesters of pregnancy, whereas FEV1 did not show a significant difference. The mean values of FVC, PEFR and MVV showed a significant decrease from first to third trimester; whereas there was a significant increase in the mean value of FEV1/FVC from first to third trimester.

\begin{tabular}{|c|c|c|c|c|c|c|}
\hline Patients & \multicolumn{2}{|c|}{ 1st Trimester } & \multicolumn{2}{c|}{ 2nd Trimester } & \multicolumn{2}{c|}{ 3rd Trimester } \\
\hline Parameters & $\begin{array}{c}\text { Hypertensive } \\
\mathbf{n = 3 0}\end{array}$ & $\begin{array}{c}\text { Non-Hypertensive } \\
\mathbf{n = 7 0}\end{array}$ & $\begin{array}{c}\text { Hypertensive } \\
\mathbf{n = 3 0}\end{array}$ & $\begin{array}{c}\text { Non-Hypertensive } \\
\mathbf{n = 7 0}\end{array}$ & $\begin{array}{c}\text { Hypertensive } \\
\mathbf{n = 3 0}\end{array}$ & $\begin{array}{c}\text { Non-Hypertensive } \\
\mathbf{n = 7 0}\end{array}$ \\
\hline FEV1 (Lit/min) & $2.22 \pm 0.06$ & $2.21 \pm 0.067$ & $2.18 \pm 0.10$ & $2.18 \pm 0.09$ & $2.12 \pm 0.09$ & $2.15 \pm 0.09$ \\
\hline FVC (Lit/min) & $2.36 \pm 0.10$ & $2.34 \pm 0.11$ & $2.20 \pm 0.08$ & $2.21 \pm 0.13$ & $2.14 \pm 0.09$ & $2.13 \pm 0.13$ \\
\hline FEV1/FVC $\%$ & $93.98 \pm 5.05$ & $94.75 \pm 5.57$ & $99.0 \pm 4.85$ & $98.77 \pm 5.73$ & $101.31 \pm 4.69$ & $101.07 \pm 6.31$ \\
\hline PEFR (Lit/sec) & $5.34 \pm 0.23$ & $5.30 \pm 0.23$ & $4.69 \pm 0.27$ & $4.67 \pm 0.23$ & $4.26 \pm 0.25$ & $4.23 \pm 0.27$ \\
\hline MVV (Lit/min) & $72.90 \pm 4.76$ & $73.38 \pm 4.95$ & $65.44 \pm 4.89$ & $65.71 \pm 4.72$ & $60.9 \pm 5.92$ & $61.12 \pm 5.48$ \\
\hline \multicolumn{7}{|c|}{ Table 4. Comparing Pulmonary Function Test in Hypertensive Women (n=30) and Non-Hypertensive Women (n= 70) with } \\
Trimester of Pregnancy \\
\hline
\end{tabular}

Table No. 4 compares the pulmonary functions in hypertensive groups with non-hypertensive group and shows no statistical significant difference in pulmonary function tests between the 2 groups.

\section{DISCUSSION}

As pregnancy advances, the enlarging uterus alters the position of the diaphragm. The rib cage and abdominal cavity undergoes structural changes in the course of pregnancy and advancing gestation due to an increase in progesterone and oestrogen levels with attendant changes in respiratory function. The expiratory level of diaphragm is elevated by the enlarging uterus, thus limiting the expiratory lung capacity and diaphragmatic excursions with advancing pregnancy.
This limitation of lung movement is however greatly compensated by the expansion of the thoracic cage and by flaring of lower ribs, thus altering the configuration of thoracic cage. ${ }^{6}$ Also, with advancing gestation, the enlarging uterus causes an increase in abdominal pressure, which decreases chest wall compliance causing a reduction in Functional Residual Capacity (FRC) and Expiratory Reserved Volume (ERV). ${ }^{7}$ The limited lung capacity is also compensated by increased movement of the diaphragm. ${ }^{8}$

During pregnancy due to the hormonal effects produced by progesterone, corticosteroids and relaxin there is certain degree of smooth muscle relaxation causing a state of bronchodilatation. ${ }^{9}$ Thus, the mechanical disadvantage to the respiratory apparatus induced by advancing pregnancy is 
compensated by decrease in airway resistance and an improved airway conductance. This is the reason for maintenance of FEV1 in the normal range throughout pregnancy.

Girija P et al ${ }^{10}$ analysed 150 normal pregnant women and found a decline in value of FEV1 from $1^{\text {st }}$ to $3^{\text {rd }}$ trimester of pregnancy; however, it was not statistically significant. But when compared with non-pregnant women as controls there is a statistically significant reduction in FEV1. Pandya et al ${ }^{1}$ and Chhabra et $\mathrm{al}^{11}$ observed that throughout pregnancy FEV1 remained within its normal range, but there was a significant decrease in $1^{\text {st }}$ trimester as compared to controls. Das et al $^{12}$ in study on 291 normal pregnant women noted that FEV1 was not affected by pregnancy. Phatak et $\mathrm{al}^{3}$ in their study on 50 normal pregnant women also found no significant change in FEV1 throughout pregnancy.

As pregnancy advances enlarging size of uterus increases intra-abdominal pressure leading to elevation of Diaphragm at term, which leads to a relative decrease in the negativity of intrapleural pressure. ${ }^{13}$ There also occurs a decrease in expiratory reserve volume and residual volume during pregnancy. The significant reduction of FVC in $3^{\text {rd }}$ trimester of pregnancy in our study was postulated to be due to significant restrictive defect caused by the enlarging uterus. Changes in lung capacities during pregnancy may also be attributed to various factors like exercise, increase in body weight, changes in chest wall, position and movement of diaphragm, mobility of thoracic cage, change in intraabdominal and intra-pleural pressures, changes in accessory muscles of respiration and mechanical effect of enlarging breasts. 3,14

The results of Monga et al, 15 Girija $\mathrm{P}$ et al, ${ }^{10}$ Mokkapatti et $\mathrm{al}^{4}$ agree with the result of present study of decrease in FVC during pregnancy, whereas the results of Gazioglu et al ${ }^{16} \mathrm{M} \mathrm{J}$ Berry et $\mathrm{al}^{17} \mathrm{~T}$ K Das et $\mathrm{al}^{12}$ show an FVC to be relatively constant during pregnancy. But the results of Anita Teli et $\mathrm{al}^{18}$ Grindheim et $\mathrm{al}^{19}$ and Surekha De et $\mathrm{al}^{9}$ are at variance from those of present study showing increase in forced vital capacity. Girija Priyadarshini et $\mathrm{al}^{10}$ in their study on 150 normal pregnant women observed a statistically significant increase in FEV1/FVC when compared to age-matched nonpregnant women; however, inter-trimester comparison of FEV1/FVC showed an increase in FEV1/FVC, but it was not statistically significant. Mokkapatti et $\mathrm{al}^{4}$ observed a significant decrease in FEV1/FVC in 45 normal pregnant women in $3^{\text {rd }}$ trimester of pregnancy compared to controls, however, found non-significant decrease in FEV1/FVC throughout pregnancy.

Panchal $\mathrm{V}$ et $\mathrm{al}^{20}$ analysed pulmonary function in 50 normal pregnant women in $3^{\text {rd }}$ trimester of pregnancy in age group of 22 - 32 years with 25 non-pregnant women as controls and found PEFR to be significantly reduced in pregnant women compared to controls. Deshpande $\mathrm{H}$ et $\mathrm{al}^{21}$ studied pulmonary function in 60 pregnant women each in $1^{\text {st }}, 2^{\text {nd }}$ and $3^{\text {rd }}$ trimester of pregnancy and compared with 60 non-pregnant women and 60 women in post-partum period and found a statistically significant reduction in PEFR from $1^{\text {st }}$ trimester to $3^{\text {rd }}$ trimester of pregnancy and that PEFR is not affected by parity and mode of delivery. Knuttgen et $\mathrm{al}^{22}$ in a study of 13 normal pregnant women noted that PEFR remains constant throughout pregnancy. This is thought to be due to effective force development at the same level of afferent nervous output brought about by altered position of diaphragm with increase in length and decrease in diameter of curvature.

The significant decrease in PEFR may be attributed to lesser force of contraction of main expiratory muscles like anterior abdominal muscles and internal intercostal muscles. ${ }^{23}$ It takes more time to come to normal, because the anterior abdominal wall muscles remain lax for a pretty long time and also the force of contraction in this muscle is very weak. Hence, it is suggested that gradual and graded active exercise for increasing the strength of the muscles of anterior abdominal wall are advised as a routine in post-natal period for early recovery of respiratory function. While most methods evaluating lung function are increasingly complicated, such that many of them can only be used in large laboratories with expensive equipment and by well trained personnel, PEFR is simple and can be used outside a wellequipped laboratory by every physician. The values however do not permit the differentiation between restrictive and obstructive ventilator defects. Therefore, though PEFR studies cannot replace FVC and FEV studies, but they add another important parameter of pulmonary function testing and since PEFR is considered as an overall test of lung function it can be used in places where such sophisticated instruments are not available.

Maximum voluntary ventilation is a dynamic test of lung function. It was first introduced by Hermannsen (1953). ${ }^{24}$ MVV does not depend on quantity of range of movements, but rather on the speed and efficiency with which filling and emptying of lungs take place. The MVV attained by any subject depends on the integrity of whole respiratory apparatus, i.e. thoracic cage, respiratory muscles, elastic recoil of lungs. Thus, the ventilatory capacity is a good measure of the overall function of lung. Normal MVV suggests good status of respiratory muscles, normal lung compliance, absence of undue resistance offered by airways and tissues and absence of any obstructive disease. As a ventilatory function test; however, MVV has certain deficiencies. Low values do not indicate the cause of ventilatory defect, which may be due to decreased stroke volume, increased resistance or a combination of both. A decline in MVV might be indicative of mechanical inhibition of the chest bellows. The decreased MVV may also be related to an increased oxygen cost per unit of work done by the respiratory muscles. ${ }^{25}$

Most of the Changes during Pregnancy tend to Increase Pulmonary Resistance. ${ }^{13}$ These changes include-

1. Increased angulation of bronchi.

2. Restriction of movement of diaphragm by gravid uterus.

3. Oedema, hyperaemia and round cell infiltration of mucosa of pharynx, larynx and bronchi.

4. Increased blood volume.

This could account for finding of decline in MVV during pregnancy.

Girija P et al ${ }^{10}$ studied pulmonary function in 150 normal pregnant women and found a statistically significant reduction in MVV with both inter-trimester comparison and with non-pregnant women as controls. Surekha De et $\mathrm{al}^{9}$ analysed 63 normal pregnant women in $1^{\text {st }}$ trimester and 25 were followed up to $3^{\text {rd }}$ trimester of pregnancy and observed a declining trend in Maximum Voluntary Ventilation (MVV) 
during pregnancy, which in $3^{\text {rd }}$ trimester was $12 \%$ lower than the mean value in $1^{\text {st }}$ trimester which were found to be statistically significant.

\section{CONCLUSION}

Chronic respiratory conditions are present in about $0.1 \%$ of women in child bearing, but not all of these are associated with limitation of activity or significant functional impairment. The results obtained in our study suggest that in pregnant women at term, respiratory distress is rarely sufficient to interfere with ordinary physical activity. However, impaired pulmonary function in pregnant women may pose additional risk during parturition as well as during operative procedures like caesarean section, which require anaesthesia. Therefore, it is extremely important to maintain strict vigilance of the serial changes occurring in pulmonary function as pregnancy advances. Regular antenatal respiratory exercises can help improve pulmonary function as pregnancy advances, so that these women can better withstand the stress of parturition and have a speedy recovery in the post-partum period. Factors complicating pregnancy like pregnancy-induced Hypertension does not affect pulmonary function.

\section{REFERENCES}

[1] Pandya KD, Chandwani S, Desai CA, et al. Study of vital capacity and timed vital capacity in normal nonpregnant and pregnant women. J Obs Gynecol India 1984;36:1053-7.

[2] Saxena SC, Rao VSC, Mudgal SA. Study of pulmonary function tests during pregnancy. J Obs Gyneco 1979;29:993-5.

[3] Phatak MS, Kurhade GA. A longitudinal study of antenatal changes in lung function tests and importance of postpartum exercises in their recovery. Indian J Physiol Pharmacol 2003;47(3):352-6.

[4] Mokkapatti R, Prasad EC, Vakatraman. Ventilatory functions in pregnancy. Indian J Physiol Pharmacol 1991;35(4):237-40.

[5] Elkus R, Popovich J. Respiratory physiology in pregnancy. Clin Chest Med 1992;13(4):555-65.

[6] McCormack MC, Wise RA. Respiratory physiology in pregnancy. Respir Med Humana Press 2009:19-23.

[7] Marx GF, Murthy PK, Orkin LR. Static compliance before and after vaginal delivery. $\mathrm{Br} \mathrm{J}$ Anaesth 1970;42(12):1100-4.

[8] McGinty AP. The comparative effects of pregnancy and phrenic nerve interruption on the diaphragm and their relation to pulmonary tuberculosis. Am J Obs Gynecol 1938;35(2):237-48.

[9] De Surekha, Bhargava P, Benawari S. Longitudinal ventilatory function (stati and dynamic) studies during different trimesters in pregnant women. J Obs Gynecol India 1984;34:812-6.
[10] Priyadarshini G, Mishra A. Effect of gestational age on pulmonary functions in pregnant Odia women. Int J Med Sci Public Heal 2014;3(12):1364-7.

[11] Chhabra $S$, Nangia $V$, Ingley KN. Changes in respiratory function tests during pregnancy. Indian J Physiol Pharmacol 1988;32(1):56-60.

[12] Das TK, Jana H. Maternal airways function during normal pregnancy. Ind J Med Sci 1991;45(10):265-8.

[13] Ganeriwal SK, Deshpande DR, Reddy BV, et al. Effect of pregnancy on pulmonary ventilation. J Obs Gynecol India 1984;36:639-41.

[14] Puranik BM, Kurhade GA, Kaore SB, et al. PEFR in pregnancy: a longitudinal study. Indian J Physiol Pharmacol 1995;39(2):135-9.

[15] Monga U, Kumari K. Pulmonary functions in Punjabi pregnant women. Ind $\mathrm{J}$ Physiol Pharmacol 2000;44(1):115-6.

[16] Gazioglu K, Kaltreider NL, Rosen M, et al. Pulmonary function during pregnancy in normal women and in patients with cardiopulmonary disease. Thorax 1970;25(4):445-50.

[17] Berry MJ, McMurray R, Katz VL. Pulmonary and ventilatory responses to pregnancy, immersion, and exercise. J Appl Physiol 1989;66(2):857-62.

[18] Teli A, Bagali S, Manjunatha A. A study of FVC, Pefr and mep in different trimesters of pregnancy. Int J Biomed Adv Res 2012;3(8):648-52.

[19] Grindheim G, Toska K, Estensen ME, et al. Changes in pulmonary function during pregnancy: a longitudinal cohort study. BJOG An Int J Obstet Gynaecol 2012;119(1):94-101.

[20] Panchal V, Dodiya D. Comparative study of dynamic lung function tests between third trimester of pregnancy and non-pregnant women. Int J Res Med 2014;3(2):158-69.

[21] Deshpande H, Madkar C, Dahiya P. A study of pulmonary function tests in different stages of pregnancy. Int J Biol Med Res 2013;4(1):2713-6.

[22] Knuttgen HG, Emerson K. Physiological response to pregnancy at rest and during exercise. J Appl Physiol 1974;36(5):549-53.

[23] Shashikala L, Sarath R. Effects of exercise on pulmonary function test. Indian J Fundamental App Life Sci 2011;1:230-1.

[24] Cotes JE, Chinn DJ, Miller RM. Lung Function: Physiology, Measurement and Application in Medicine, sixth edition. Wiley online library 2009:5-6.

[25] Singhal U, Saxena K. Effect of anemia on respiratory and metabolic parameters during third trimester of pregnancy. Indian J Physiol Pharmacol 1987;31(2):130-5. 